OPEN ACCESS

Edited by:

Gaetano Santulli,

Columbia University, USA

Reviewed by:

Celestino Sardu,

Second University of Naples, Italy; Leiden University Medical Center,

Netherlands

Qi Yuan,

Columbia University, USA

${ }^{*}$ Correspondence:

Gary Tse

gary.tse@doctors.org.uk

Yu Huang

yu-huang@cuhk.edu.hk

Specialty section This article was submitted to

Cardiac Electrophysiology,

a section of the journal

Frontiers in Physiology

Received: 04 May 2016

Accepted: 11 July 2016

Published: 03 August 2016

Citation:

Tse G, Yan BP, Chan YWF, Tian XY and Huang $Y$ (2016) Reactive Oxygen

Species, Endoplasmic Reticulum Stress and Mitochondrial Dysfunction:

The Link with Cardiac

Arrhythmogenesis.

Front. Physiol. 7:313.

doi: 10.3389/fphys.2016.00313

\section{Reactive Oxygen Species, Endoplasmic Reticulum Stress and Mitochondrial Dysfunction: The Link with Cardiac Arrhythmogenesis}

\author{
Gary Tse ${ }^{1,2 *}$, Bryan P. Yan ${ }^{2,3}$, Yin W. F. Chan ${ }^{4}$, Xiao Yu Tian ${ }^{5}$ and Yu Huang ${ }^{5 *}$ \\ ${ }^{1}$ Li Ka Shing Faculty of Medicine, School of Biomedical Sciences, University of Hong Kong, Hong Kong, China, ${ }^{2}$ Department \\ of Medicine and Therapeutics, Faculty of Medicine, Chinese University of Hong Kong, Hong Kong, China, ${ }^{3}$ Department of \\ Epidemiology and Preventive Medicine, Monash University, Melbourne, VIC, Australia, ${ }^{4}$ Department of Psychology, School of \\ Biological Sciences, University of Cambridge, Cambridge, UK, ${ }^{5}$ Faculty of Medicine, School of Biomedical Sciences, \\ Chinese University of Hong Kong, Hong Kong, China
}

Background: Cardiac arrhythmias represent a significant problem globally, leading to cerebrovascular accidents, myocardial infarction, and sudden cardiac death. There is increasing evidence to suggest that increased oxidative stress from reactive oxygen species (ROS), which is elevated in conditions such as diabetes and hypertension, can lead to arrhythmogenesis.

Method: A literature review was undertaken to screen for articles that investigated the effects of ROS on cardiac ion channel function, remodeling and arrhythmogenesis.

Results: Prolonged endoplasmic reticulum stress is observed in heart failure, leading to increased production of ROS. Mitochondrial ROS, which is elevated in diabetes and hypertension, can stimulate its own production in a positive feedback loop, termed ROS-induced ROS release. Together with activation of mitochondrial inner membrane anion channels, it leads to mitochondrial depolarization. Abnormal function of these organelles can then activate downstream signaling pathways, ultimately culminating in altered function or expression of cardiac ion channels responsible for generating the cardiac action potential (AP). Vascular and cardiac endothelial cells become dysfunctional, leading to altered paracrine signaling to influence the electrophysiology of adjacent cardiomyocytes. All of these changes can in turn produce abnormalities in AP repolarization or conduction, thereby increasing likelihood of triggered activity and reentry.

Conclusion: ROS plays a significant role in producing arrhythmic substrate. Therapeutic strategies targeting upstream events include production of a strong reducing environment or the use of pharmacological agents that target organelle-specific proteins and ion channels. These may relieve oxidative stress and in turn prevent arrhythmic complications in patients with diabetes, hypertension, and heart failure.

Keywords: oxidative stress, reactive oxygen species, endoplasmic reticulum, mitochondria, conduction, repolarization, remodeling, arrhythmia 


\section{INTRODUCTION}

Cardio-metabolic disorders such as diabetes mellitus and hypertension place significant burdens on the healthcare system worldwide. Over the past decades, their prevalence has been steadily increasing, due to aging and a rising level of obesity in the population (Chan and Woo, 2010; Wong et al., 2011). These disorders are leading causes of mortality and morbidity, which are traditionally attributed to cardiovascular accidents, myocardial infarction, and heart failure. Cardiac arrhythmias have increasingly been recognized as a cause of death. Diabetes may affect the prognosis of heart failure subjects differently at the clinical (Sardu et al., 2014b) and epigenetic level (Sardu et al., 2016). This article explores the normal functions of the endoplasmic reticulum (ER) and mitochondria, and synthesize current experimental data to illustrate how increased oxidative and metabolic stress can lead to dysfunction of these organelles, and in turn can initiate signaling cascades that modify the ion channel function and promote electrophysiological and structural remodeling, which ultimately promotes arrhythmogenesis.

\section{NORMAL FUNCTIONS OF THE ENDOPLASMIC RETICULUM, SARCOPLASMIC RETICULUM, AND MITOCHONDRIA}

The ER is the intracellular organelle responsible for protein synthesis, folding, maturation, and assembly before they are exported to the Golgi apparatus, cytosol and plasma membrane. The oxidative environment within the lumen ensures proper formation of tertiary and quaternary structures, aided by chaperones and abundance of $\mathrm{Ca}^{2+}$ for interactions between them. Abnormalities in these factors can lead to unfolding or misfolding of proteins, which in turn can accumulate within the ER lumen. This would produce ER stress and elicit the unfolded protein response (UPR), which serves to reduce protein synthesis, enhance protein folding ability and aid misfolded or unfolded protein to cellular degradation pathways (Tsang et al., 2010).

The sarcoplasmic reticulum (SR) of cardiomyocytes is responsible for excitation-contraction coupling and subsequent contractile activation. Thus, dihydropyridine receptors (DIHRs) are found in the transverse tubular system and have molecular configurations that are steeply voltage-dependent, enabling them to act as voltage sensors. They are allosterically coupled to RyRs, the $\mathrm{Ca}^{2+}$ release channels in the SR. A depolarizing wave from the plasma membrane can spread to the transverse tubules, thereby activating the DIHRs, which then allows RyRs to dissociate from DIHRs and release the luminal $\mathrm{Ca}^{2+}$, inducing further release from the SR by a mechanism called $\mathrm{Ca}^{2+}$-induced $\mathrm{Ca}^{2+}$-release. This intracellular $\mathrm{Ca}^{2+}$ is important for initiation of contractile activity, as it binds to $\mathrm{Ca}^{2+}$-sensitive proteins including troponin, myosin, and actin. Relaxation occurs when intracellular $\mathrm{Ca}^{2+}$ returns to normal levels by following mechanisms: passive efflux mediated by the electrogenic sodium-calcium exchanger (NCX) out of the cell, active transport into the SR by sarcoplasmic reticulum $\mathrm{Ca}^{2+}$-ATPase (SERCA) and passive diffusion into the mitochondria via the mitochondrial $\mathrm{Ca}^{2+}$ uniporter (Choi et al., 2014). Finally, the SR may have functions that are traditionally ascribed to the ER, such as protein synthesis and folding (Glembotski, 2012).

The mitochondria are the site of energy supply where ATP synthesis occurs by oxidative phosphorylation, with additional roles such as regulation of apoptosis, redox status and reactive oxygen species (ROS) production (Dikalov, 2011). ATP synthesis involves electron transfer through the respiratory chain from complex I through to complex IV, culminating in protons being pumped from the mitochondrial matrix into the intermembrane space (Chance and Williams, 1955). Mitochondria are the main source of ROS, which are derived mostly from complexes I and III, as well as enzymes such as the alpha-ketoglutarate dehydrogenase complex and those involved in fatty acid betaoxidation (St-Pierre et al., 2002; Starkov et al., 2004; Tahara et al., 2009; Brand, 2010). Oxygen free radical production is much more efficient by reverse electron transfer dependent on succinate (through complex I to $\mathrm{NAD}^{+}$) than forward electron transfer with NADH (Panov et al., 2007). This reverse electron transfer is an important mechanism of ROS production in many pathological conditions such as hypertension (Nazarewicz et al., 2013).

\section{INCREASED OXIDATIVE STRESS AND INTRACELLULAR ORGANELLE DYSFUNCTION IN CARDIO-METABOLIC DISORDERS}

Increased oxidative stress from excessive ROS production appears to underlie pro-arrhythmic cardiac modeling in cardiometabolic disorders (Figure 1). There is an increased arrhythmic burden, conditioning primary and secondary outcomes in patients with metabolic syndrome (Sardu et al., 2014a). ROS refers to superoxide, hydrogen peroxide, peroxynitrite, and hydroxyl radicals, which are unstable molecular species that can damage proteins and lipids within the cell, and activate intracellular signaling cascades. They can be generated by activation of NADPH oxidase or xanthine oxidase, uncoupling of nitric oxide synthase (NOS) or leakage of electrons from the mitochondria during oxidative phosphorylation. Normally, cardiomyocytes are protected from ROS-mediated damage by several mechanisms. Firstly, enzymes such as superoxide dismutase (SOD), catalase and glutathione peroxidase breakdown ROS into water and oxygen. Secondly, a series of redox defense systems can inactivate ROS, which are reduced glutathione (GSH), NADH, thioredoxin, and free radical scavengers such as vitamins $C$ and $E$ (Schafer and Buettner, 2001; Yamamoto et al., 2003; Zima et al., 2004; Gasparetto et al., 2005). Abnormal NADH accumulation, observed in diabetes, can lead to reductive stress, pseudohypoxia and subsequent, paradoxical oxidative stress; interested readers are directed to this article here (Yan, 2014). Increased oxidative stress is associated with abnormal function of intracellular organelles such as the ER and 


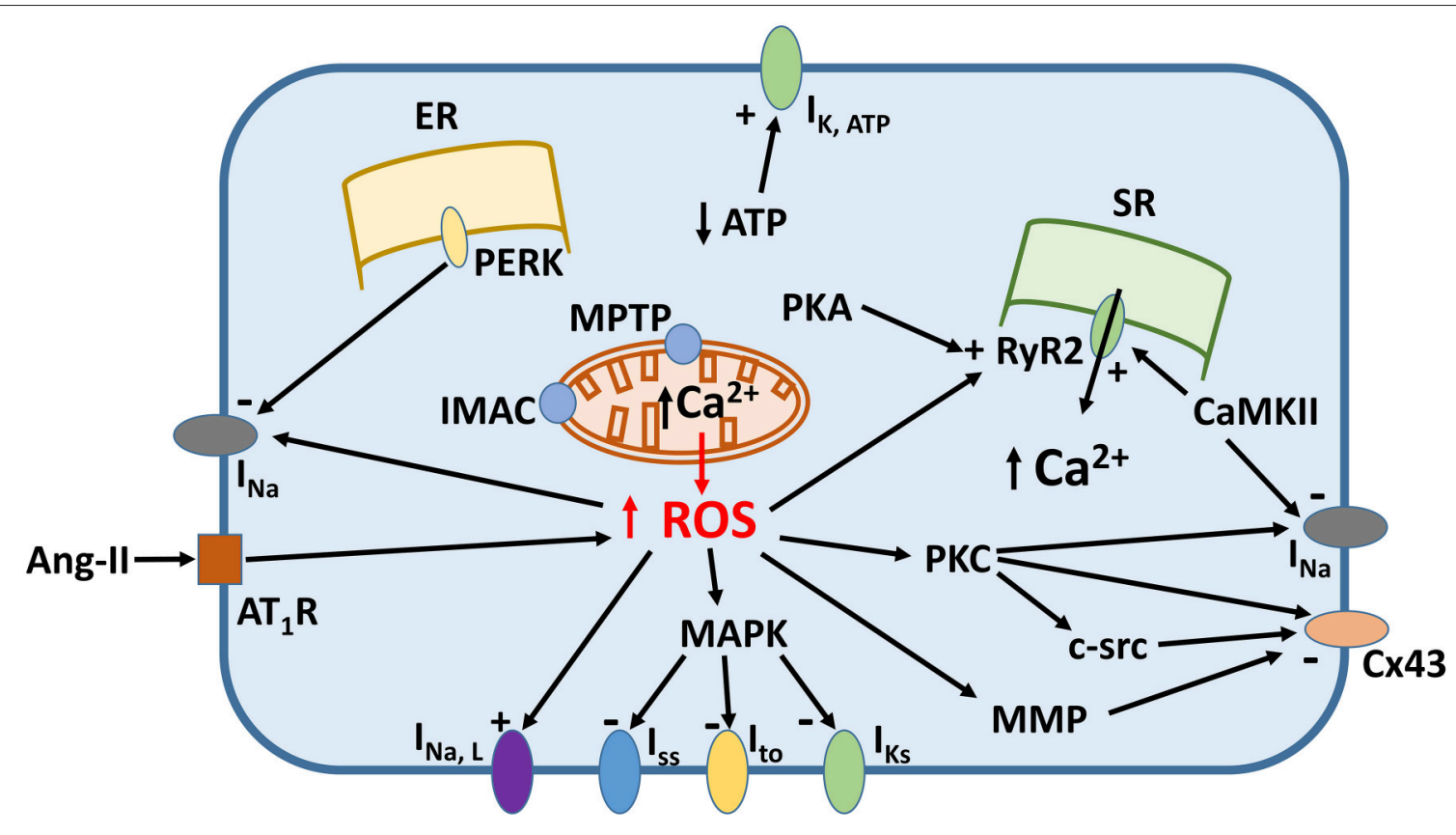

FIGURE 1 | Signaling mechanisms linking increased reactive oxygen species (ROS) production and ion channel remodeling.

mitochondria (Wong et al., 2013; Cheang et al., 2014; Lenna et al., 2014; Murugan et al., 2015; Zhang et al., 2015). Since both the ER and mitochondria are associated with $\mathrm{Ca}^{2+}$ release and uptake in cardiomyocytes and abnormal $\mathrm{Ca}^{2+}$ handling in these cells can cause arrhythmias, it is not surprisingly that ED could be the initial trigger. ROS can also promote structural and electrophysiological remodeling, leading to abnormalities in action potential (AP) conduction or repolarization (Tse and Yeo, 2015), and in turn to triggered activity or circus-type reentry (Figure 2). These mechanisms are considered in further detail below.

\section{TRIGGERED ACTIVITY AND REENTRY CAN RESULT FROM ROS GENERATION}

\section{Action Potential Prolongation and Abnormal $\mathrm{Ca}^{2+}$ Handling Can Lead to Triggered Activity}

Triggered activity results from afterdepolarizations, which are secondary depolarization events arising prematurely before generation of the next AP (Cranefield, 1977; January et al., 1991). They can occur before or after full repolarization, termed early afterdepolarizations (EADs) or delayed afterdepolarizations (DADs), respectively. EADs typically develop when action potential durations (APDs) are prolonged, due to a greater magnitude of inward depolarizing currents $\left(I_{\mathrm{Na}}, I_{\mathrm{Ca}}, I_{\mathrm{NCX}}\right)$ compared to the outward repolarizing currents $\left(I_{\mathrm{Kr}}, I_{\mathrm{Ks}}, I_{\mathrm{K} 1}\right)$ (Tse, 2015). This would enable reactivation of the L-type calcium channel, thereby increasing $I_{\mathrm{Ca}, \mathrm{L}}$ (January and Riddle, 1989). By contrast, DADs occur when there is intracellular $\mathrm{Ca}^{2+}$ overload, which induces $\mathrm{Ca}^{2+}$-induced $\mathrm{Ca}^{2+}$ release from the ER. This activates the sodium-calcium exchange current, $I_{\mathrm{NCX}}$, the nonselective cationic current, $I_{\mathrm{NS}}$ and the calcium-activated chloride current, $I_{\mathrm{Cl}, \mathrm{Ca}}$ (Guinamard et al., 2004). The net result of EAD or DAD is membrane depolarization and initiation of another AP. If the afterdepolarizations are not sufficiently large to induce an AP, they can exacerbate the regional differences in repolarization, which may lead to alternans, unidirectional conduction block and reentry (Tse et al., in press).

Electrophysiological remodeling is observed in heart failure, with mostly downregulation of ion channels, leading to APD prolongation and/or altered calcium release, predisposing to EADs, DADs, and reentry (Marfella et al., 2013; Tse et al., 2016a). Moreover, the activities of ion channels may condition heart failure and arrhythmic state, regulating epigenetic mechanisms related to cardiac adaptive responses (Sardu et al., 2014c, 2015). The renin-angiotensin system (RAS) becomes activated in diabetes, hypertension and heart failure. This pathway is responsible for enzymatic cleavage of angiotensinogen, which is converted to angiotensin I and angiotensin II (Ang-II) by renin and angiotensin converting enzyme (ACE), respectively. Ang-II can activate the $\mathrm{AT}_{1}$ receptor, which increases NADPH oxidase activity to promote ROS production, resulting in downregulation of the calcium-independent transient outward $\mathrm{K}^{+}$channel $\left(I_{\text {to }}\right)$ (Lebeche et al., 2006). ROS can increase the activity of MAPKactivated protein kinase-1 ( $\left.990^{\text {rsk }}\right)$, which phosphorylates and decreases the activity of $I_{\text {to, f }}, I_{\mathrm{K}}$, slow and $I_{\mathrm{SS}}$ channels (Lu et al., 2008). ROS can prolongs the late sodium current, $I_{\mathrm{Na}, \mathrm{L}}$ (Ma et al., 2005; Song Y. et al., 2006).

Moreover, prolonged activation of UPR during ER stress in heart failure leads to increased oxidative stress, downregulation 


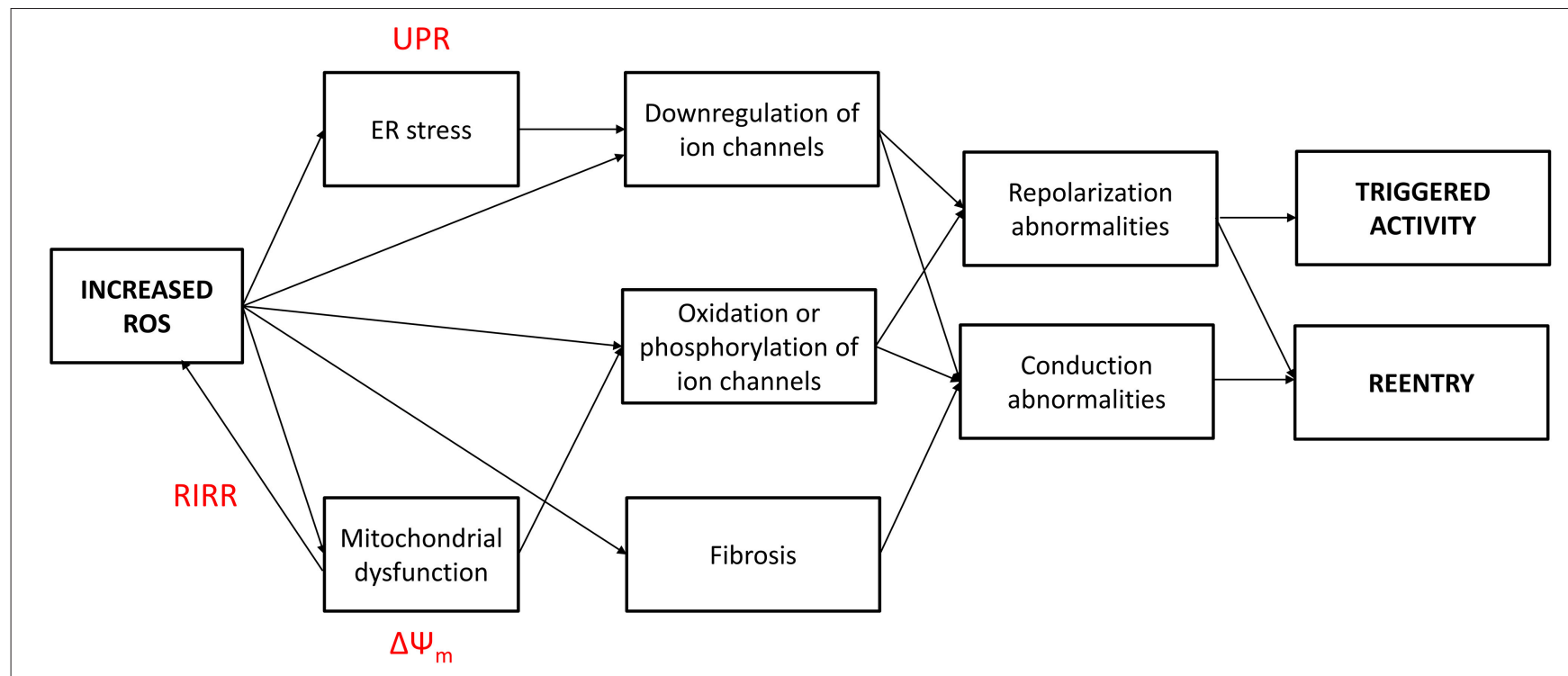

FIGURE 2 | Increased reactive oxygen species (ROS) production in cardio-metabolic disorders induce both conduction and repolarization abnormalities, thereby leading to both triggered and reentrant arrhythmogenesis. UPR, unfolded protein response; RIRR, ROS-induced ROS release; $\Delta \Psi_{\mathrm{m}}$, mitochondrial inner membrane potential.

of $I_{\text {to }}$ and increased $\mathrm{Ca}^{2+}$ release from the SR. RyR2, the cardiacspecific isoform, is affected by post-translational modification from intracellular signaling cascades. Thus, they can be oxidized by ROS or reactive carbonyl species (RCS) (Eager et al., 1997; Xu et al., 1998; Bidasee et al., 2003), or phosphorylation by protein kinases such as protein kinase $\mathrm{A}$ or $\mathrm{Ca}^{2+} /$ calmodulin-dependent protein kinase II (CAMKII), leading to abnormal gating (Witcher et al., 1991; Hain et al., 1995; Wehrens et al., 2004). This in turn leads to reduced amplitude but increased frequency of $\mathrm{Ca}^{2+}$ sparks and increased RyR2 sensitivity to $\mathrm{Ca}^{2+}$ activation (Shao et al., 2007, 2009). RyR2 decoupling from LTCCs can lead to desynchronized $\mathrm{Ca}^{2+}$ release (Song L.S. et al., 2006). ROS derived from the mitochondria could inhibit SERCA and stimulate RyR2, thereby activating NCX, $\mathrm{Ca}^{2+}$-sensitive cationic channels and $\mathrm{Ca}^{2+}$-induced $\mathrm{Ca}^{2+}$-release (Li et al., 2015).

Aside from regulation of energy production, mitochondria can also take up and release $\mathrm{Ca}^{2+}$ through several mechanisms, and may therefore serve as a buffer system. It may be that under physiological conditions, mitochondria do not have a major role in buffering $\mathrm{Ca}^{2+}$ (O'Rourke and Blatter, 2009; Williams et al., 2013). However, in heart failure, there is significant $\mathrm{Ca}^{2+}$ overload in both the cytoplasm and the mitochondria of cardiomyocytes (Santulli et al., 2015b). Experiments in a mouse model of heart failure generated by myocardial infarction, leaky RyR2 was shown to be responsible for mitochondrial $\mathrm{Ca}^{2+}$ overload (Santulli et al., 2015b). This would lead to mitochondrial dysfunction and increased ROS production. A recent study found that in mice with RyR2 mutations leading to diastolic $\mathrm{Ca}^{2+}$ leak, increased RyR2 oxidation, mitochondrial dysfunction and increased ROS production are observed, and these findings were associated with an increase in atrial fibrillation (AF) susceptibility (Xie et al., 2015a). Other studies also support the critical role of increased oxidative stress in the development and maintenance of AF. Thus, ROS from the atria correlated with the duration and substrate of AF in goats and humans (Reilly et al., 2011). Increased mitochondrial oxidative stress leading to RyR2 leak has also been observed in the ventricles of a peroxisome proliferatoractivated receptor- $\gamma$ (PPARg) cardiac overexpression mouse model (Joseph et al., 2016). The net electrophysiological effect was AP prolongation and development of ectopic activity.

Together, all of the above mechanisms can prolong APD and/or lead to abnormal $\mathrm{Ca}^{2+}$ release, inducing EADs and DADs and therefore triggered activity.

\section{Disruption of Normal AP Conduction or Repolarization and Abnormal $\mathrm{Ca}^{2+}$ Handling Can Lead to Reentry}

The conduction of cardiac APs through the working myocardium has traditionally been described by the core conductor model. This is based on the cable theory, whose equations can be derived by applying Kirchoff's circuit law. Conduction velocity (CV) is determined by both passive and active properties of the cell membrane. The passive components are axial resistance of the myoplasm $\left(r_{i}\right)$, resistance of the extracellular space $\left(r_{o}\right)$, and membrane capacitance $\left(\mathrm{C}_{\mathrm{m}}\right)$. Diameter of the cardiomyocyte is important because it alters both $r_{i}$ and $C_{m}$. Active membrane properties refer to the voltage-gated conductances, mainly the sodium current $\left(I_{\mathrm{Na}}\right)$ mediating the AP upstroke. This model was subsequently modified to account for the presence of gap junctions (Saffitz et al., 1994; Rohr, 2004). Each gap junction consists of two connexons, which are hexameric proteins of the connexin $(\mathrm{Cx})$ subunit, mediating electrical communication by electrotonic spread. However, it forms a high resistance pathway that can decrease $\mathrm{CV}$ and produce discontinuous propagation (Spach et al., 1981; Spach, 2003). Its expression is 
not equally distributed across the myocardium, higher numbers are found at the ends of myocytes compared to the lateral aspects of the cell membrane (Kumar and Gilula, 1996). Consequently, CV is higher in the longitudinal direction than in the transverse direction, which is termed anisotropic conduction (Sano et al., 1959; Clerc, 1976). The role of ephaptic coupling has been neglected until recently, involving a direct electrical field mechanism for mediating conduction (Rhett and Gourdie, 2012; Lin and Keener, 2013; Rhett et al., 2013; Veeraraghavan et al., 2014a,b,c; George et al., 2015; Veeraraghavan et al., 2015). Finally, myocardial fibrosis cam reduce the coupling between cardiomyocytes, increasing $r_{i}$, and enhance the coupling between fibroblasts and cardiomyocytes (Camelliti et al., 2004; Chilton et al., 2007), increasing $c_{m}$, both of which would reduce $C V$ and increase the dispersion of CV (Tse and Yeo, 2015).

Circus-type reentry occurs when an AP travels around an obstacle and re-excites its site of origin, and requires both conduction and repolarization abnormalities (Tse, 2015; Tse et al., 2016d,h). Firstly, conduction velocity (CV) must be sufficiently slowed to prevent the AP depolarization wavefront from colliding with its repolarization wave back, where the local myocardium is still in its effective refractory period (ERP) and cannot be excited. If this occurs, conduction will be blocked and the AP will extinguish, resulting in a break of the reentrant circuit. Secondly, unidirectional conduction block must be present. Otherwise, wavefront APs traveling in opposite directions can collide and extinguish, thereby terminating the arrhythmia. Thirdly, an obstacle can be a non-conducting or refractory region, arising from structural defects such as interstitial fibrosis, or dynamically from ectopic activity. When the excitation wavelength of the AP wave $(\lambda, \mathrm{CV} \times \mathrm{ERP})$ is smaller than the path length, reentry can occur. The ERP usually coincides with the APD. Thus, reduction in $\mathrm{CV}$, APD, or ERP can promote reentry by reducing $\lambda$, whereas increased $\lambda$ reduces the likelihood of reentry (Tse et al., 2012; Choy et al., 2016; Tse, 2016b; Tse et al., 2016c,e,f,g,h,i,k,l).

All of the above factors are influenced by ROS, altering ion channel function and promoting extracellular matrix (ECM) remodeling, which together would produce conduction and repolarization abnormalities, thereby leading to reentry (Tse and Yeo, 2015). For example, the SCN5A gene encoding for the cardiac $\mathrm{Na}^{+}$channels is regulated by the transcription factor NF- $\kappa$ B (Shang and Dudley, 2005). Elevated angiotensin II levels and the increased oxidative stress increase NF- $\kappa$ B binding to the SCN5A promoter region, thereby decreasing its transcriptional activity (Shang et al., 2008). Ang-II can also downregulate Cx43 and Cx40, reducing intercellular coupling (Kasi et al., 2007). During ER stress, PERK activation downregulates the $\mathrm{Na}^{+}$ channels, although this is a non-ion channel specific effect since $I_{\text {to }}$ expression is also reduced (Gao et al., 2013). Furthermore, abnormal $\mathrm{Ca}^{2+}$ release can have direct and indirect effects. $\mathrm{Ca}^{2+}$ can bind directly to the evolutionarily conserved EF hand motif at the carboxyl end of the $\mathrm{Na}^{+}$channel, thereby producing a depolarizing shift in its voltage-dependent inactivation, which prolongs the late sodium current, $I_{\mathrm{Na}, \mathrm{L}}$ (Wingo et al., 2004; Song Y. et al., 2006). Moreover, the $\mathrm{Na}^{+}$channel also possesses an IQ domain for $\mathrm{Ca}^{2+} / \mathrm{CaM}$ binding and additionally several serine/threonine residues amenable to phosphorylation, for example by CaMKII (Ashpole et al., 2012), leading to channel inactivation (Tan et al., 2002).

$\mathrm{Ca}^{2+}$ can activate protein kinase C (PKC) (Luo and Weinstein, 1993), which can phosphorylate both $\mathrm{Na}^{+}$channels (Qu et al., 1996) and Cx43 (Moreno et al., 1994; Kwak et al., 1995) to reduce $I_{\mathrm{Na}}$ and $I_{\text {gap }}$, respectively. $\mathrm{Ca}^{2+}$ overload is also associated with dephosphorylation of gap junctions (Huang et al., 1999), leading to their uncoupling (Beardslee et al., 2000) and lateralization (Smith et al., 1991; Lampe et al., 2000). Interestingly, a recent report demonstrated that streptozotocin-induced diabetic mice have increased phosphorylation levels of $\mathrm{Cx} 43$ at the serine 262 residue (Palatinus and Gourdie, 2016). Previous experiments showed that Ser 262 phosphorylation of $\mathrm{Cx} 43$ is associated with a cardiac injury-resistant state (Srisakuldee et al., 2009). Poor myocardial healing could increase the likelihood of conduction abnormalities, which would increase arrhythmogenicity. Finally, homocysteine, which is raised in hypertension and diabetes, causes EEC dysfunction and apoptosis (Miller et al., 2000; Wei et al., 2010), suppression of superoxide dismutase and activation of matrix metalloproteinases (MMPs) in the plasma membrane, causing Cx43 disruption (Rosenberger et al., 2006). Increased $\mathrm{Ca}^{2+}$ leak through the RyR2 channels results in $\mathrm{Ca}^{2+}$ alternans, which in turn can drive APD alternans and reentry (Xie et al., 2013).

Mitochondrial ROS production is elevated in diabetes and hypertension (Kakkar et al., 1995; Kanazawa et al., 2002; Dikalov and Ungvari, 2013). Mitochondrial ROS can itself increase its own production in a positive feedback loop, termed ROS-induced ROS release (RIRR), a mechanism recently recognized as a key initiator of mitochondrial depolarization (Zorov et al., 2000). Thus, Ang-II can activate the $\mathrm{AT}_{1}$ receptor, which stimulates Nox2, an enzyme that catalyzes electron transfer from NADPH to oxygen, generating oxygen free radicals and hydrogen peroxide. The oxygen free radical can enter the mitochondria and activate PKC $\varepsilon$ at the mitochondrial inner membrane (Jaburek et al., 2006). The downstream target is mitochondrial $K_{\text {ATP }}$ channels (mitoK $\mathrm{ATP}_{\mathrm{AT}}$ ), resulting in reverse electron transfer from complex II to complex I, which generates more oxygen free radicals (Dikalov et al., 2014). The latter can be converted to hydrogen peroxide, activating c-src (Aikawa et al., 1997) and in turn further activating NADPH oxidases, production of free radicals and NOS uncoupling. Mitochondrial $\mathrm{K}_{\text {ATP }}$ channel activation in cardiomyocytes in diabetes led to impaired APD adaptation, which promoted the occurrence of VT (Xie et al., 2015b). AngII mediated mitochondrial ROS production can lead to c-src activation and reduced Cx43 expression (Sovari et al., 2013). Homocysteine can activate mitochondrial MMPs, which leads to opening the mitochondrial permeability transition pore (MPTP) (Moshal et al., 2008; Montaigne et al., 2013) and collapse of the mitochondrial inner membrane potential $\left(\Delta \Psi_{\mathrm{m}}\right)$ (Brown et al., 2010).

ROS can also activate the mitochondrial inner membrane anion channels (IMAC) to result in mitochondrial depolarization (Yang et al., 2010). RIRR-induced regional mitochondrial depolarization results in the formation of a metabolic sink (Zhou et al., 2014). Uncoupling of oxidative phosphorylation can reverse mitochondrial ATP synthase, thereby depleting 
intracellular ATP. This causes sarcolemmal $\mathrm{K}_{\text {ATP }}$ activation, increased $\mathrm{K}^{+}$efflux and APD shortening (Garlid et al., 1997; Zhou et al., 2014). Moreover, ROS can promote myocardial fibrosis via a NOX4-mediated, ROS-ERK1/2-MAP Kinasedependent mechanism (Aragno et al., 2006; Kuroda et al., 2010).

Together, the above factors can lead to reduction in $\mathrm{CV}$, together with increased repolarization gradients, can promote unidirectional conduction block and reentry (Tse et al., in press).

\section{ENDOTHELIAL-CARDIOMYOCYTE COUPLING, PARACRINE SIGNALING, AND ARRHYTHMOGENESIS}

Endothelial cells form the inner lining of blood vessels, thereby controlling vascular tone by releasing vasodilators, such as nitric oxide (NO), prostacyclin and endothelial-dependent hyperpolarizing factor. In the heart, cardiac endothelial cells (CECs), including myocardial coronary endothelial cells (MCECs) lining the coronary microvasaculature and endocardial endothelial cells (EECs), outnumber cardiomyocytes (CM) with a 3:1 ratio and have roles distinct from those of the vascular endothelium, such as regulation of cardiomyocyte growth and modulation of electrical and mechanical functions (Baldwin and Artman, 1998; Brutsaert, 2003). They may do so in a paracrine manner by secreting messengers such as NO, prostaglandins, endothelin and angiotensin II. These may act on specific receptors on the plasma membrane of cardiomyocytes (e.g., Ang-II binding to $\mathrm{AT}_{1} \mathrm{R}$ ), diffuse through the membrane of cardiomyocytes (in the case of gasotransmitters such as NO), or enter via gap junctions, to activate their downstream effector. Gap junctions are non-specific pores that also allows the spread of molecules up to $1 \mathrm{kDa}$ in molecular mass (Harris, 2001; Weber et al., 2004). However, MCECs lack gap junctions and their communication with surrounding cells occur by other mechanisms.

Endothelial dysfunction is a hallmark of diabetes mellitus, hypertension and heart disease, playing a role in the initiation and progression of vascular dysfunction, eventually resulting in atherosclerosis, thrombosis and arrhythmogenesis (Wong et al., 2013). This usually refers to dysfunction of vascular endothelial cells that include the MCECs. However, EECs also become dysfunctional in diabetes and hypertension (Chu et al., 1995; Popov et al., 1996; Brutsaert, 2003). These could initiate signaling cascades that ultimately modify ion channel function and promote electrophysiological and structural remodeling in the myocardium to produce an arrhythmic substrate (Miller et al., 2002; Rosenberger et al., 2006; Moshal et al., 2008; Givvimani et al., 2011).

\section{CLINICAL RELEVANCE AND FUTURE PERSPECTIVES}

Reduction in oxidative stress is an attractive strategy for preventing ROS-induced ion channel dysfunction, electrophysiological and structural remodeling. In keeping with this theory, exogenous application of strong reducing agents such as hydrogen sulfide was shown to reduce cardiac fibrosis. Increasing the expression of enzymes breaking down free radicals, such as SOD (Dikalova et al., 2010). Glutathione peroxidase overexpression in diabetic rat hearts prevented adverse structural remodeling by reducing fibrosis and improving diastolic dysfunction (Matsushima et al., 2006). This would be expected to reduce the degree of conduction abnormalities and thereby increase the threshold for arrhythmogenesis.

Much of the cellular oxidative stress is derived from the mitochondria, which promotes arrhythmogenesis (Xie et al., 2015a). Therefore, antioxidants specifically targeting this organelle would be a logical strategy for anti-arrhythmic therapy. Thus, experiments in genetically modified, ACE8/8 mice with RAS activation have demonstrated therapeutic effects of a mitochondrial-specific antioxidant, but not a general antioxidant, in preventing ventricular arrhythmias (Sovari et al., 2013). Altered mitochondrial bioenergetics characterized by mitochondrial depolarization is a key initiating factor of an adverse positive feedback loop of causing RIRR. Interestingly, inhibition of the MPTP by cyclosporine A did not prevent the collapse of $\Delta \Psi_{\mathrm{m}}$ (Berkich et al., 2003), whereas IMAC inhibition using the mitochondrial benzodiazepine receptor did (Akar et al., 2005). Recent work has demonstrated that patients with catecholaminergic polymorphic VT, in whom the RyR2 is mutated and leaky, insulin secretion and glucose metabolism were dysregulated (Santulli et al., 2015a). Since mitochondrial $\mathrm{Ca}^{2+}$ overload is due to a leaky RyR2 (Santulli et al., 2015b), ryanodine receptor stabilizers can be used to reduce this leak and reduce arrhythmic burden (Lehnart et al., 2006). ER stress is also a potential target, since a prolonged UPR can induce adverse electrophysiological remodeling. For example, overexpression of chaperone proteins Grp78 and Grp94 can increase binding to UPR sensors and abnormal proteins, in turn alleviating ER and oxidative stress as well as $\mathrm{Ca}^{2+}$ overload (Vitadello et al., 2003; Pan et al., 2004).

Many of the above findings have been derived from animal models, which are amenable to genetic and pharmacological manipulation (Tse et al., 2012; Chen et al., 2016; Tse et al., 2016 b,c,e,f,g,k, in press). In these systems, electrophysiological consequences of ion channel mutation or dysfunction can be examined using different recording methods such as monophasic action potential or bipolar electrogram recordings, and optical mapping (Vigmond and Bardakjian, 1995; Vigmond and Leon, 1999; Vigmond, 2005; Vigmond et al., 2009; Tse et al., 2016j). Furthermore, detection of magnetic signals has been used in clinical practice: for example magnetic resonance imaging is excellent for characterization of cardiac structures in humans but are less practical for use in animal studies (Vassiliou et al., 2014; Tse et al., 2015a,b). Magnetocardiography (MCG) can be used to diagnose and predict the risk of cardiac arrhythmias in humans (Steinhoff et al., 2004; Sato et al., 2012; Kwong et al., 2013; Ito et al., 2014; Yoshida et al., 2015). A micromagnetometer array with a superconducting 
quantum interference device (SQUID) can be used for noncontact recording of MCGs from mice and has the potential for high-throughput use to screen for pro- or anti-arrhythmic effects of pharmacological agents (Komamura et al., 2008). Given the evidence presented here, it is clear that increased ROS can lead to intracellular organelle dysfunction and arrhythmias in cardio-metabolic disorders such as diabetes mellitus and hypertension. It is therefore prudent that the at-risk population is identified, which would enable early intervention to reduce arrhythmic mortality (Cardoso et al., 2003; Salles et al., 2005; Stettler et al., 2007; Clemente et al., 2012; Tse, 2016a,c; Tse and Yan, 2016a,b).

Nevertheless, because of the complex nature of cardiac spatiotemporal dynamics, a systems approach is needed to determine the net effect of a pharmacological agent on arrhythmogenicity. Identification of the molecular events is important for developing therapeutic strategies to reduce oxidative stress, which could slow or even reverse disease progression of cardio-metabolic disorders, which would in

\section{REFERENCES}

Aikawa, R., Komuro, I., Yamazaki, T., Zou, Y., Kudoh, S., Tanaka, M., et al. (1997). Oxidative stress activates extracellular signal-regulated kinases through Src and Ras in cultured cardiac myocytes of neonatal rats. J. Clin. Invest. 100, 1813-1821. doi: 10.1172/JCI119709

Akar, F. G., Aon, M. A., Tomaselli, G. F., and O'Rourke, B. (2005). The mitochondrial origin of postischemic arrhythmias. J. Clin. Invest. 115, 3527-3535. doi: 10.1172/JCI25371

Aragno, M., Mastrocola, R., Medana, C., Catalano, M. G., Vercellinatto, I., Danni, O., et al. (2006). Oxidative stress-dependent impairment of cardiac-specific transcription factors in experimental diabetes. Endocrinology 147, 5967-5974. doi: 10.1210/en.2006-0728

Ashpole, N. M., Herren, A. W., Ginsburg, K. S., Brogan, J. D., Johnson, D. E., Cummins, T. R., et al. (2012). Ca2+/calmodulin-dependent protein kinase II (CaMKII) regulates cardiac sodium channel NaV1.5 gating by multiple phosphorylation sites. J. Biol. Chem. 287, 19856-19869. doi: 10.1074/jbc.M111.322537

Baldwin, H. S., and Artman, M. (1998). Recent advances in cardiovascular development: promise for the future. Cardiovasc. Res. 40, 456-468. doi: 10.1016/S0008-6363(98)00277-6

Beardslee, M. A., Lerner, D. L., Tadros, P. N., Laing, J. G., Beyer, E. C., Yamada, K. A., et al. (2000). Dephosphorylation and intracellular redistribution of ventricular connexin 43 during electrical uncoupling induced by ischemia. Circ. Res. 87, 656-662. doi: 10.1161/01.RES.87.8.656

Berkich, D. A., Salama, G., and LaNoue, K. F. (2003). Mitochondrial membrane potentials in ischemic hearts. Arch. Biochem. Biophys. 420, 279-286. doi: 10.1016/j.abb.2003.09.021

Bidasee, K. R., Nallani, K., Besch, H. R. Jr., and Dincer, U. D. (2003). Streptozotocin-induced diabetes increases disulfide bond formation on cardiac ryanodine receptor (RyR2). J. Pharmacol. Exp. Ther. 305, 989-998. doi: 10.1124/jpet.102.046201

Brand, M. D. (2010). The sites and topology of mitochondrial superoxide production. Exp. Gerontol. 45, 466-472. doi: 10.1016/j.exger.2010.01.003

Brown, D. A., Aon, M. A., Frasier, C. R., Sloan, R. C., Maloney, A. H., Anderson, E. J., et al. (2010). Cardiac arrhythmias induced by glutathione oxidation can be inhibited by preventing mitochondrial depolarization. J. Mol. Cell. Cardiol. 48, 673-679. doi: 10.1016/j.yjmcc.2009.11.011

Brutsaert, D. L. (2003). Cardiac endothelial-myocardial signaling: its role in cardiac growth, contractile performance, and rhythmicity. Physiol. Rev. 83, 59-115. doi: 10.1152/physrev.00017.2002 turn reduce the risk of cardiac arrhythmias complicating these conditions in this patient population.

\section{AUTHOR CONTRIBUTIONS}

GT: Design of manuscript; drafted and critically revised the manuscript for important intellectual content; preparation of figures. BY: Interpreted primary research papers; critically revised the manuscript for important intellectual content. YC: Critically revised the manuscript for important intellectual content. XT and YH: Drafted and critically revised the manuscript for important intellectual content.

\section{ACKNOWLEDGMENTS}

GT received a BBSRC Doctoral Training Award, and thanks the Croucher Foundation of Hong Kong for support of his clinical assistant professorship.

Camelliti, P., Green, C. R., LeGrice, I., and Kohl, P. (2004). Fibroblast network in rabbit sinoatrial node: structural and functional identification of homogeneous and heterogeneous cell coupling. Circ. Res. 94, 828-835. doi: 10.1161/01.RES.0000122382.19400.14

Cardoso, C. R., Salles, G. F., and Deccache, W. (2003). Prognostic value of QT interval parameters in type 2 diabetes mellitus: results of a long-term followup prospective study. J. Diabetes Complicat. 17, 169-178. doi: 10.1016/S10568727(02)00206-4

Chan, R. S., and Woo, J. (2010). Prevention of overweight and obesity: how effective is the current public health approach. Int. J. Environ. Res. Public Health 7, 765-783. doi: 10.3390/ijerph7030765

Chance, B., and Williams, G. R. (1955). Respiratory enzymes in oxidative phosphorylation. III. The steady state. J. Biol. Chem. 217, 409-427.

Cheang, W. S., Tian, X. Y., Wong, W. T., Lau, C. W., Lee, S. S., Chen, Z. Y., et al. (2014). Metformin protects endothelial function in diet-induced obese mice by inhibition of endoplasmic reticulum stress through $5^{\prime}$ adenosine monophosphate-activated protein kinase-peroxisome proliferator-activated receptor delta pathway. Arterioscler. Thromb. Vasc. Biol. 34, 830-836. doi: 10.1161/ATVBAHA.113.301938

Chen, Z., Sun, B., Tse, G., Jiang, J., and Xu, W. (2016). Reversibility of both sinus node dysfunction and reduced HCN4 mRNA expression level in an atrial tachycardia pacing model of tachycardia-bradycardia syndrome in rabbit hearts. Int. J. Clin. Exp. Pathol.

Chilton, L., Giles, W. R., and Smith, G. L. (2007). Evidence of intercellular coupling between co-cultured adult rabbit ventricular myocytes and myofibroblasts. J. Physiol. 583, 225-236. doi: 10.1113/jphysiol.2007.135038

Choi, E., Cha, M. J., and Hwang, K. C. (2014). Roles of calcium regulating MicroRNAs in cardiac ischemia-reperfusion injury. Cells 3, 899-913. doi: 10.3390/cells3030899

Choy, L., Yeo, J. M., Tse, V., Chan, S. P., and Tse, G. (2016). Cardiac disease and arrhythmogenesis: lessons from mouse studies. Int. J. Cardiol. Heart Vasc. 12, 1-10. doi: 10.1016/j.ijcha.2016.05.005

Chu, G. X., Ling, Q., and Guo, Z. G. (1995). Effects of endocardial endothelium in myocardial mechanics of hypertrophied myocardium of rats. Zhongguo Yao Li Xue Bao 16, 352-356.

Clemente, D., Pereira, T., and Ribeiro, S. (2012). Ventricular repolarization in diabetic patients: characterization and clinical implications. Arq. Bras. Cardiol. 99, 1015-1022. doi: 10.1590/S0066-782X2012005000095

Clerc, L. (1976). Directional differences of impulse spread in trabecular muscle from mammalian heart. J. Physiol. 255, 335-346. doi: 10.1113/jphysiol.1976.sp011283 
Cranefield, P. F. (1977). Action potentials, afterpotentials, and arrhythmias. Circ. Res. 41, 415-423. doi: 10.1161/01.RES.41.4.415

Dikalov, S. (2011). Cross talk between mitochondria and NADPH oxidases. Free Radic. Biol. Med. 51, 1289-1301. doi: 10.1016/j.freeradbiomed.2011.06.033

Dikalov, S. I., Nazarewicz, R. R., Bikineyeva, A., Hilenski, L., Lassegue, B., Griendling, K. K., et al. (2014). Nox2-induced production of mitochondrial superoxide in angiotensin II-mediated endothelial oxidative stress and hypertension. Antioxid. Redox Signal. 20, 281-294. doi: 10.1089/ars.2012.4918

Dikalov, S. I., and Ungvari, Z. (2013). Role of mitochondrial oxidative stress in hypertension. Am. J. Physiol. Heart Circ. Physiol. 305, H1417-H1427. doi: 10.1152/ajpheart.00089.2013

Dikalova, A. E., Bikineyeva, A. T., Budzyn, K., Nazarewicz, R. R., McCann, L., Lewis, W., et al. (2010). Therapeutic targeting of mitochondrial superoxide in hypertension. Circ. Res. 107, 106-116. doi: 10.1161/CIRCRESAHA.109.214601

Eager, K. R., Roden, L. D., and Dulhunty, A. F. (1997). Actions of sulfhydryl reagents on single ryanodine receptor $\mathrm{Ca}(2+)$-release channels from sheep myocardium. Am. J. Physiol. 272, C1908-C1918.

Gao, G., Xie, A., Zhang, J., Herman, A. M., Jeong, E. M., Gu, L., et al. (2013). Unfolded protein response regulates cardiac sodium current in systolic human heart failure. Circ. Arrhythm. Electrophysiol. 6, 1018-1024. doi: 10.1161/CIRCEP.113.000274

Garlid, K. D., Paucek, P., Yarov-Yarovoy, V., Murray, H. N., Darbenzio, R. B., D'Alonzo, A. J., et al. (1997). Cardioprotective effect of diazoxide and its interaction with mitochondrial ATP-sensitive $\mathrm{K}+$ channels. Possible mechanism of cardioprotection. Circ. Res. 81, 1072-1082. doi: 10.1161/01.RES.81.6.1072

Gasparetto, C., Malinverno, A., Culacciati, D., Gritti, D., Prosperini, P. G., Specchia, G., et al. (2005). Antioxidant vitamins reduce oxidative stress and ventricular remodeling in patients with acute myocardial infarction. Int. J. Immunopathol. Pharmacol. 18, 487-496. doi: 10.1177/039463200501800308

George, S. A., Sciuto, K. J., Lin, J., Salama, M. E., Keener, J. P., Gourdie, R. G., et al. (2015). Extracellular sodium and potassium levels modulate cardiac conduction in mice heterozygous null for the Connexin 43 gene. Pflugers Arch. 467, 2287-2297. doi: 10.1007/s00424-015-1698-0

Givvimani, S., Qipshidze, N., Tyagi, N., Mishra, P. K., Sen, U., and Tyagi, S. C. (2011). Synergism between arrhythmia and hyperhomo-cysteinemia in structural heart disease. Int. J. Physiol. Pathophysiol. Pharmacol. 3, 107-119.

Glembotski, C. C. (2012). Roles for the sarco-/endoplasmic reticulum in cardiac myocyte contraction, protein synthesis, and protein quality control. Physiology 27, 343-350. doi: 10.1152/physiol.00034.2012

Guinamard, R., Chatelier, A., Demion, M., Potreau, D., Patri, S., Rahmati, M., et al. (2004). Functional characterization of a $\mathrm{Ca}(2+)$-activated non-selective cation channel in human atrial cardiomyocytes. J. Physiol. 558, 75-83. doi: 10.1113/jphysiol.2004.063974

Hain, J., Onoue, H., Mayrleitner, M., Fleischer, S., and Schindler, H. (1995). Phosphorylation modulates the function of the calcium release channel of sarcoplasmic reticulum from cardiac muscle. J. Biol. Chem. 270, 2074-2081. doi: 10.1074/jbc.270.5.2074

Harris, A. L. (2001). Emerging issues of connexin channels: biophysics fills the gap. Q. Rev. Biophys. 34, 325-472. doi: 10.1017/S0033583501003705

Huang, X. D., Sandusky, G. E., and Zipes, D. P. (1999). Heterogeneous loss of connexin 43 protein in ischemic dog hearts. J. Cardiovasc. Electrophysiol. 10, 79-91. doi: 10.1111/j.1540-8167.1999.tb00645.x

Ito, Y., Shiga, K., Yoshida, K., Ogata, K., Kandori, A., Inaba, T., et al. (2014). Development of a magnetocardiography-based algorithm for discrimination between ventricular arrhythmias originating from the right ventricular outflow tract and those originating from the aortic sinus cusp: a pilot study. Heart Rhythm. 11, 1605-1612. doi: 10.1016/j.hrthm.2014.05.032

Jaburek, M., Costa, A. D., Burton, J. R., Costa, C. L., and Garlid, K. D. (2006). Mitochondrial PKC epsilon and mitochondrial ATP-sensitive $\mathrm{K}+$ channel copurify and coreconstitute to form a functioning signaling module in proteoliposomes. Circ. Res. 99, 878-883. doi: 10.1161/01.RES.0000245106.80628.d3

January, C. T., Chau, V., and Makielski, J. C. (1991). Triggered activity in the heart: cellular mechanisms of early after-depolarizations. Eur. Heart J. 12, 4-9. doi: 10.1093/eurheartj/12.suppl_F.4
January, C. T., and Riddle, J. M. (1989). Early afterdepolarizations: mechanism of induction and block. A role for L-type Ca2+ current. Circ. Res. 64, 977-990. doi: 10.1161/01.RES.64.5.977

Joseph, L. C., Subramanyam, P., Radlicz, C., Trent, C. M., Iyer, V., Colecraft, H. M., et al. (2016). Mitochondrial oxidative stress during cardiac lipid overload causes intracellular calcium leak and arrhythmia. Heart Rhythm. doi: 10.1016/j.hrthm.2016.05.002. [Epub ahead of print].

Kakkar, R., Kalra, J., Mantha, S. V., and Prasad, K. (1995). Lipid peroxidation and activity of antioxidant enzymes in diabetic rats. Mol. Cell. Biochem. 151, 113-119. doi: 10.1007/BF01322333

Kanazawa, A., Nishio, Y., Kashiwagi, A., Inagaki, H., Kikkawa, R., and Horiike, K. (2002). Reduced activity of mtTFA decreases the transcription in mitochondria isolated from diabetic rat heart. Am. J. Physiol. Endocrinol. Metab. 282, E778E785. doi: 10.1152/ajpendo.00255.2001

Kasi, V. S., Xiao, H. D., Shang, L. L., Iravanian, S., Langberg, J., Witham, E. A., et al. (2007). Cardiac-restricted angiotensin-converting enzyme overexpression causes conduction defects and connexin dysregulation. Am. J. Physiol. Heart Circ. Physiol. 293, H182-H192. doi: 10.1152/ajpheart.00684.2006

Komamura, K., Adachi, Y., Miyamoto, M., Kawai, J., Haruta, Y., and Uehara, G. (2008). Micro-Magnetocardiography system with a single-chip SQUID magnetometer array for QT analysis and diagnosis of myocardial injury in small animals. IEEE Trans. Biomed. Circuits Syst. 2, 260-268. doi: 10.1109/TBCAS.2008.2003979

Kumar, N. M., and Gilula, N. B. (1996). The gap junction communication channel. Cell 84, 381-388. doi: 10.1016/S0092-8674(00)81282-9

Kuroda, J., Ago, T., Matsushima, S., Zhai, P., Schneider, M. D., and Sadoshima, J. (2010). NADPH oxidase 4 (Nox4) is a major source of oxidative stress in the failing heart. Proc. Natl. Acad. Sci. U.S.A. 107, 15565-15570. doi: 10.1073/pnas.1002178107

Kwak, B. R., Hermans, M. M., De Jonge, H. R., Lohmann, S. M., Jongsma, H. J., and Chanson, M. (1995). Differential regulation of distinct types of gap junction channels by similar phosphorylating conditions. Mol. Biol. Cell 6, 1707-1719. doi: $10.1091 / \mathrm{mbc} .6 .12 .1707$

Kwong, J. S., Leithauser, B., Park, J. W., and Yu, C. M. (2013). Diagnostic value of magnetocardiography in coronary artery disease and cardiac arrhythmias: a review of clinical data. Int. J. Cardiol. 167, 1835-1842. doi: 10.1016/j.ijcard.2012.12.056

Lampe, P. D., TenBroek, E. M., Burt, J. M., Kurata, W. E., Johnson, R. G., and Lau, A. F. (2000). Phosphorylation of connexin 43 on serine368 by protein kinase C regulates gap junctional communication. J. Cell Biol. 149, 1503-1512. doi: 10.1083/jcb.149.7.1503

Lebeche, D., Kaprielian, R., and Hajjar, R. (2006). Modulation of action potential duration on myocyte hypertrophic pathways. J. Mol. Cell. Cardiol. 40, 725-735. doi: 10.1016/j.yjmcc.2006.01.018

Lehnart, S. E., Terrenoire, C., Reiken, S., Wehrens, X. H. T., Song, L.-S., Tillman, E. J., et al. (2006). Stabilization of cardiac ryanodine receptor prevents intracellular calcium leak and arrhythmias. Proc. Natl. Acad. Sci. U.S.A. 103, 7906-7910. doi: 10.1073/pnas.0602133103

Lenna, S., Han, R., and Trojanowska, M. (2014). Endoplasmic reticulum stress and endothelial dysfunction. IUBMB Life 66, 530-537. doi: 10.1002/iub.1292

Li, Q., Su, D., O'Rourke, B., Pogwizd, S. M., and Zhou, L. (2015). Mitochondriaderived ROS bursts disturb $\mathrm{Ca} 2+$ cycling and induce abnormal automaticity in guinea pig cardiomyocytes: a theoretical study. Am. J. Physiol. Heart Circ. Physiol. 308, H623-H636. doi: 10.1152/ajpheart.00493.2014

Lin, J., and Keener, J. P. (2013). Ephaptic coupling in cardiac myocytes. IEEE Trans. Biomed. Eng. 60, 576-582. doi: 10.1109/TBME.2012.2226720

Lu, Z., Abe, J., Taunton, J., Lu, Y., Shishido, T., McClain, C., et al. (2008). Reactive oxygen species-induced activation of p90 ribosomal S6 kinase prolongs cardiac repolarization through inhibiting outward K+ channel activity. Circ. Res. 103, 269-278. doi: 10.1161/CIRCRESAHA.107.166678

Luo, J. H., and Weinstein, I. B. (1993). Calcium-dependent activation of protein kinase $\mathrm{C}$. The role of the $\mathrm{C} 2$ domain in divalent cation selectivity. J. Biol. Chem. $268,23580-23584$.

Ma, J. H., Luo, A. T., and Zhang, P. H. (2005). Effect of hydrogen peroxide on persistent sodium current in guinea pig ventricular myocytes. Acta Pharmacol. Sin. 26, 828-834. doi: 10.1111/j.1745-7254.2005.00154.x 
Marfella, R., Di Filippo, C., Potenza, N., Sardu, C., Rizzo, M. R., Siniscalchi, M., et al. (2013). Circulating microRNA changes in heart failure patients treated with cardiac resynchronization therapy: responders vs. non-responders. Eur. J. Heart Fail. 15, 1277-1288. doi: 10.1093/eurjhf/hft088

Matsushima, S., Kinugawa, S., Ide, T., Matsusaka, H., Inoue, N., Ohta, Y., et al. (2006). Overexpression of glutathione peroxidase attenuates myocardial remodeling and preserves diastolic function in diabetic heart. Am. J. Physiol. Heart Circ. Physiol. 291, H2237-H2245. doi: 10.1152/ajpheart.00427.2006

Miller, A., Mujumdar, V., Palmer, L., Bower, J. D., and Tyagi, S. C. (2002). Reversal of endocardial endothelial dysfunction by folic acid in homocysteinemic hypertensive rats. Am. J. Hypertens. 15, 157-163. doi: 10.1016/S08957061(01)02286-5

Miller, A., Mujumdar, V., Shek, E., Guillot, J., Angelo, M., Palmer, L., et al. (2000). Hyperhomocyst(e)inemia induces multiorgan damage. Heart Vessels 15, 135-143. doi: 10.1007/s003800070030

Montaigne, D., Marechal, X., Lefebvre, P., Modine, T., Fayad, G., Dehondt, H., et al. (2013). Mitochondrial dysfunction as an arrhythmogenic substrate: a translational proof-of-concept study in patients with metabolic syndrome in whom post-operative atrial fibrillation develops. J. Am. Coll. Cardiol. 62, 1466-1473. doi: 10.1016/j.jacc.2013.03.061

Moreno, A. P., Saez, J. C., Fishman, G. I., and Spray, D. C. (1994). Human connexin43 gap junction channels. Regulation of unitary conductances by phosphorylation. Circ. Res. 74, 1050-1057. doi: 10.1161/01.RES.74.6.1050

Moshal, K. S., Metreveli, N., Frank, I., and Tyagi, S. C. (2008). Mitochondrial MMP activation, dysfunction and arrhythmogenesis in hyperhomocysteinemia. Curr. Vasc. Pharmacol. 6, 84-92. doi: 10.2174/157016108783955301

Murugan, D., Lau, Y. S., Lau, W. C., Mustafa, M. R., and Huang, Y. (2015). Angiotensin 1-7 protects against angiotensin II-induced endoplasmic reticulum stress and endothelial dysfunction via mas receptor. PLOS ONE 10:e0145413. doi: 10.1371/journal.pone.0145413

Nazarewicz, R. R., Dikalova, A. E., Bikineyeva, A., and Dikalov, S. I. (2013). Nox2 as a potential target of mitochondrial superoxide and its role in endothelial oxidative stress. Am. J. Physiol. Heart Circ. Physiol. 305, H1131-H1140. doi: 10.1152/ajpheart.00063.2013

O'Rourke, B., and Blatter, L. A. (2009). Mitochondrial Ca2+ uptake: tortoise or hare? J. Mol. Cell. Cardiol. 46, 767-774. doi: 10.1016/j.yjmcc.2008.12.011

Palatinus, J. A., and Gourdie, R. G. (2016). Diabetes increases cryoinjury size with associated effects on $\mathrm{Cx} 43$ gap junction function and phosphorylation in the mouse heart. J. Diabetes Res. 2016:8789617. doi: 10.1155/2016/ 8789617

Pan, Y. X., Lin, L., Ren, A. J., Pan, X. J., Chen, H., Tang, C. S., et al. (2004). HSP70 and GRP78 induced by endothelin-1 pretreatment enhance tolerance to hypoxia in cultured neonatal rat cardiomyocytes. J. Cardiovasc. Pharmacol. 44(Suppl. 1), S117-S120. doi: 10.1097/01.fjc.0000166234.11336.a9

Panov, A., Dikalov, S., Shalbuyeva, N., Hemendinger, R., Greenamyre, J. T., and Rosenfeld, J. (2007). Species- and tissue-specific relationships between mitochondrial permeability transition and generation of ROS in brain and liver mitochondria of rats and mice. Am. J. Physiol. Cell Physiol. 292, C708-C718. doi: 10.1152/ajpcell.00202.2006

Popov, D., Sima, A., Stern, D., and Simionescu, M. (1996). The pathomorphological alterations of endocardial endothelium in experimental diabetes and diabetes associated with hyperlipidemia. Acta Diabetol. 33, 41-47. doi: 10.1007/BF00571939

Qu, Y., Rogers, J. C., Tanada, T. N., Catterall, W. A., and Scheuer, T. (1996). Phosphorylation of S1505 in the cardiac Na+ channel inactivation gate is required for modulation by protein kinase C. J. Gen. Physiol. 108, 375-379. doi: 10.1085/jgp.108.5.375

Reilly, S. N., Jayaram, R., Nahar, K., Antoniades, C., Verheule, S., Channon, K. M., et al. (2011). Atrial sources of reactive oxygen species vary with the duration and substrate of atrial fibrillation: implications for the antiarrhythmic effect of statins. Circulation 124, 1107-1117. doi: 10.1161/CIRCULATIONAHA.111.029223

Rhett, J. M., and Gourdie, R. G. (2012). The perinexus: a new feature of Cx43 gap junction organization. Heart Rhythm. 9, 619-623. doi: 10.1016/j.hrthm.2011.10.003

Rhett, J. M., Veeraraghavan, R., Poelzing, S., and Gourdie, R. G. (2013). The perinexus: sign-post on the path to a new model of cardiac conduction? Trends Cardiovasc. Med. 23, 222-228. doi: 10.1016/j.tcm.2012.12.005
Rohr, S. (2004). Role of gap junctions in the propagation of the cardiac action potential. Cardiovasc. Res. 62, 309-322. doi: 10.1016/j.cardiores.2003.11.035

Rosenberger, D., Moshal, K. S., Kartha, G. K., Tyagi, N., Sen, U., Lominadze, D., et al. (2006). Arrhythmia and neuronal/endothelial myocyte uncoupling in hyperhomocysteinemia. Arch. Physiol. Biochem. 112, 219-227. doi: 10.1080/13813450601093443

Saffitz, J. E., Kanter, H. L., Green, K. G., Tolley, T. K., and Beyer, E. C. (1994). Tissue-specific determinants of anisotropic conduction velocity in canine atrial and ventricular myocardium. Circ. Res. 74, 1065-1070. doi: 10.1161/01.RES.74.6.1065

Salles, G. F., Deccache, W., and Cardoso, C. R. (2005). Usefulness of QTinterval parameters for cardiovascular risk stratification in type 2 diabetic patients with arterial hypertension. J. Hum. Hypertens. 19, 241-249. doi: 10.1038/sj.jhh.1001815

Sano, T., Takayama, N., and Shimamoto, T. (1959). Directional difference of conduction velocity in the cardiac ventricular syncytium studied by microelectrodes. Circ. Res. 7, 262-267. doi: 10.1161/01.RES.7.2.262

Santulli, G., Pagano, G., Sardu, C., Xie, W., Reiken, S., D’Ascia, S. L., et al. (2015a). Calcium release channel RyR2 regulates insulin release and glucose homeostasis. J. Clin. Invest. 125, 1968-1978. doi: 10.1172/JCI79273

Santulli, G., Xie, W., Reiken, S. R., and Marks, A. R. (2015b). Mitochondrial calcium overload is a key determinant in heart failure. Proc. Natl. Acad. Sci. U.S.A. 112, 11389-11394. doi: 10.1073/pnas.1513047112

Sardu, C., Barbieri, M., Rizzo, M. R., Paolisso, P., Paolisso, G., and Marfella, R. (2016). Cardiac resynchronization therapy outcomes in type 2 diabetic patients: role of microRNA changes. J. Diabetes Res. 2016:7292564. doi: $10.1155 / 2016 / 7292564$

Sardu, C., Carreras, G., Katsanos, S., Kamperidis, V., Pace, M. C., Passavanti, M. B., et al. (2014a). Metabolic syndrome is associated with a poor outcome in patients affected by outflow tract premature ventricular contractions treated by catheter ablation. BMC Cardiovasc. Disord. 14:176. doi: 10.1186/1471-2261-14-176

Sardu, C., Marfella, R., and Santulli, G. (2014b). Impact of diabetes mellitus on the clinical response to cardiac resynchronization therapy in elderly people. $J$. Cardiovasc. Transl. Res. 7, 362-368. doi: 10.1007/s12265-014-9545-9

Sardu, C., Marfella, R., Santulli, G., and Paolisso, G. (2014c). Functional role of miRNA in cardiac resynchronization therapy. Pharmacogenomics 15, 1159-1168. doi: 10.2217/pgs.14.76

Sardu, C., Santamaria, M., Paolisso, G., and Marfella, R. (2015). microRNA expression changes after atrial fibrillation catheter ablation. Pharmacogenomics 16, 1863-1877. doi: 10.2217/pgs.15.117

Sato, Y., Yoshida, K., Ogata, K., Inaba, T., Tada, H., Sekiguchi, Y., et al. (2012). An increase in right atrial magnetic strength is a novel predictor of recurrence of atrial fibrillation after radiofrequency catheter ablation. Circ. J. 76, 1601-1608. doi: 10.1253/circj.CJ-11-1419

Schafer, F. Q., and Buettner, G. R. (2001). Redox environment of the cell as viewed through the redox state of the glutathione disulfide/glutathione couple. Free Radic. Biol. Med. 30, 1191-1212. doi: 10.1016/S0891-5849(01)00480-4

Shang, L. L., and Dudley, S. C. Jr. (2005). Tandem promoters and developmentally regulated $5^{\prime}$ - and $3^{\prime}$-mRNA untranslated regions of the mouse Scn5a cardiac sodium channel. J. Biol. Chem. 280, 933-940. doi: 10.1074/jbc.M409977200

Shang, L. L., Sanyal, S., Pfahnl, A. E., Jiao, Z., Allen, J., Liu, H., and Dudley, S. C. Jr. (2008). NF-kappaB-dependent transcriptional regulation of the cardiac scn5a sodium channel by angiotensin II. Am. J. Physiol. Cell Physiol. 294, C372-C379. doi: 10.1152/ajpcell.00186.2007

Shao, C. H., Rozanski, G. J., Patel, K. P., and Bidasee, K. R. (2007). Dyssynchronous (non-uniform) Ca2 + release in myocytes from streptozotocin-induced diabetic rats. J. Mol. Cell Cardiol. 42, 234-246. doi: 10.1016/j.yjmcc.2006.08.018

Shao, C.-H., Wehrens, X. H. T., Wyatt, T. A., Parbhu, S., Rozanski, G. J., Patel, K. P., et al. (2009). Exercise training during diabetes attenuates cardiac ryanodine receptor dysregulation. J. Appl. Physiol. 106, 1280-1292. doi: 10.1152/japplphysiol.91280.2008

Smith, J. H., Green, C. R., Peters, N. S., Rothery, S., and Severs, N. J. (1991). Altered patterns of gap junction distribution in ischemic heart disease. An immunohistochemical study of human myocardium using laser scanning confocal microscopy. Am. J. Pathol. 139, 801-821.

Song, L. S., Sobie, E. A., McCulle, S., Lederer, W. J., Balke, C. W., and Cheng, H. (2006). Orphaned ryanodine receptors in the failing heart. Proc. Natl. Acad. Sci. U.S.A. 103, 4305-4310. doi: 10.1073/pnas.0509324103 
Song, Y., Shryock, J. C., Wagner, S., Maier, L. S., and Belardinelli, L. (2006). Blocking late sodium current reduces hydrogen peroxide-induced arrhythmogenic activity and contractile dysfunction. J. Pharmacol. Exp. Ther. 318, 214-222. doi: 10.1124/jpet.106.101832

Sovari, A. A., Rutledge, C. A., Jeong, E. M., Dolmatova, E., Arasu, D., Liu, H., et al. (2013). Mitochondria oxidative stress, connexin 43 remodeling, and sudden arrhythmic death. Circ. Arrhythm. Electrophysiol. 6, 623-631. doi: 10.1161/CIRCEP.112.976787

Spach, M. S. (2003). Transition from a continuous to discontinuous understanding of cardiac conduction. Circ. Res. 92, 125-126. doi: 10.1161/01.RES.0000056973.54305.67

Spach, M. S., Miller, W. T. III., Geselowitz, D. B., Barr, R. C., Kootsey, J. M., and Johnson, E. A. (1981). The discontinuous nature of propagation in normal canine cardiac muscle. Evidence for recurrent discontinuities of intracellular resistance that affect the membrane currents. Circ. Res. 48, 39-54. doi: 10.1161/01.RES.48.1.39

Srisakuldee, W., Jeyaraman, M. M., Nickel, B. E., Tanguy, S., Jiang, Z. S., and Kardami, E. (2009). Phosphorylation of connexin-43 at serine 262 promotes a cardiac injury-resistant state. Cardiovasc. Res. 83, 672-681. doi: $10.1093 / \mathrm{cvr} / \mathrm{cvp} 142$

Starkov, A. A., Fiskum, G., Chinopoulos, C., Lorenzo, B. J., Browne, S. E., Patel, M. S., et al. (2004). Mitochondrial alpha-ketoglutarate dehydrogenase complex generates reactive oxygen species. J. Neurosci. 24, 7779-7788. doi: 10.1523/JNEUROSCI.1899-04.2004

Steinhoff, U., Knappe-Grueneberg, S., Schnabel, A., Trahms, L., Smith, F., Langley, P., et al. (2004). Magnetocardiography for pharmacology safety studies requiring high patient throughput and reliability. J. Electrocardiol. 37(Suppl.), 187-192. doi: 10.1016/j.jelectrocard.2004.08.055

Stettler, C., Bearth, A., Allemann, S., Zwahlen, M., Zanchin, L., Deplazes, M., et al. (2007). QTc interval and resting heart rate as long-term predictors of mortality in type 1 and type 2 diabetes mellitus: a 23-year follow-up. Diabetologia 50, 186-194. doi: 10.1007/s00125-006-0483-1

St-Pierre, J., Buckingham, J. A., Roebuck, S. J., and Brand, M. D. (2002). Topology of superoxide production from different sites in the mitochondrial electron transport chain. J. Biol. Chem. 277, 44784-44790. doi: 10.1074/jbc.M207217200

Tahara, E. B., Navarete, F. D., and Kowaltowski, A. J. (2009). Tissue, substrate-, and site-specific characteristics of mitochondrial reactive oxygen species generation. Free Radic. Biol. Med. 46, 1283-1297. doi: 10.1016/j.freeradbiomed.2009.02.008

Tan, H. L., Kupershmidt, S., Zhang, R., Stepanovic, S., Roden, D. M., Wilde, A. A., et al. (2002). A calcium sensor in the sodium channel modulates cardiac excitability. Nature 415, 442-447. doi: 10.1038/415442a

Tsang, K. Y., Chan, D., Bateman, J. F., and Cheah, K. S. (2010). In vivo cellular adaptation to ER stress: survival strategies with double-edged consequences. J. Cell Sci. 123, 2145-2154. doi: 10.1242 /jcs. 068833

Tse, G. (2015). Mechanisms of cardiac arrhythmias. J. Arrhythm. 32, 75-81. doi: 10.1016/j.joa.2015.11.003

Tse, G. (2016a). Both transmural dispersion of repolarization and transmural dispersion of refractoriness are poor predictors of arrhythmogenicity: a role for the index of cardiac electrophysiological balance (QT/QRS)? J. Geriatr. Cardiol.

Tse, G. (2016b). Novel indices for stratifying arrhythmic risk: (Tpeak-Tend)/QRS and (Tpeak-Tend)/(QT x QRS). J. Geriatr. Cardiol.

Tse, G. (2016c). (Tpeak-Tend)/QRS and (Tpeak-Tend)/(QT x QRS): novel markers for predicting arrhythmic risk in Brugada syndrome. Europace. doi: 10.17863/CAM.113

Tse, G., Ali, A., Alpendurada, F., Prasad, S., Raphael, C. E., and Vassiliou, V. (2015a). Tuberculous constrictive pericarditis. Res. Cardiovasc. Med. 4:e29614. doi: 10.5812/cardiovascmed.29614

Tse, G., Ali, A., Prasad, S. K., Vassiliou, V., and Raphael, C. E. (2015b). Atypical case of post-partum cardiomyopathy: an overlap syndrome with arrhythmogenic right ventricular cardiomyopathy? BJR|Case Rep. 1:20150182. doi: 10.1259/bjrcr.20150182

Tse, G., Hothi, S. S., Grace, A. A., and Huang, C. L. (2012). Ventricular arrhythmogenesis following slowed conduction in heptanol-treated, Langendorff-perfused mouse hearts. J. Physiol. Sci. 62, 79-92. doi: $10.1007 / \mathrm{s} 12576-011-0187-2$
Tse, G., Lai, E. T., Lee, A. P., Yan, B. P., and Wong, S. H. (2016a). Electrophysiological mechanisms of gastrointestinal arrhythmogenesis: lessons from the heart. Front. Physiol. 7:230. doi: 10.3389/fphys.2016.00230

Tse, G., Lai, E. T., Tse, V., and Yeo, J. M. (in press). Molecular and electrophysiological mechanisms underlying cardiac arrhythmogenesis in diabetes mellitus. J. Diabetes Res.

Tse, G., Lai, E. T., Yeo, J. M., and Yan, B. P. (2016b). Electrophysiological mechanisms of Bayés syndrome: insights from clinical and mouse studies. Front. Physiol. 7:188. doi: 10.3389/fphys.2016.00188

Tse, G., Lai, E. T., Yeo, J. M., and Yan, B. P. (2016c). What is the arrhythmic substrate in viral myocarditis? Insights from clinical and animal studies. Front. Physiol. 7:308. doi: 10.3389/fphys.2016.00308

Tse, G., Lai, T. H., Yeo, J. M., Tse, V., and Wong, S. H. (2016d). Mechanisms of electrical activation and conduction in the gastrointestinal system: lessons from cardiac electrophysiology. Front. Physiol. 7:182. doi: 10.3389/fphys.2016.00182

Tse, G., Sun, B., Wong, S. T., Tse, V., and Yeo, J. M. (2016e). Ventricular antiarrhythmic effects of hypercalcaemia treatment in hyperkalaemic, Langendorffperfused mouse hearts. Biomed. Rep. doi: 10.3892/br.2016.577

Tse, G., Tse, V., and Yeo, J. M. (2016f). Ventricular anti arrhythmic effects of heptanol in hypokalaemic, Langendorff perfused mouse hearts. Biomed. Rep. 4, 313-324. doi: 10.3892/br.2016.577

Tse, G., Tse, V., Yeo, J. M., and Sun, B. (2016g). Atrial anti-arrhythmic effects of heptanol in Langendorff-perfused mouse hearts. PLoS ONE 11:e0148858. doi: 10.1371/journal.pone. 0148858

Tse, G., Wong, S. T., Tse, V., Lee, Y. T., Lin, H. Y., and Yeo, J. M. (in press). Cardiac dynamics: alternans and arrhythmogenesis. J Arrhythm. doi: 10.1016/j.joa.2016.02.009

Tse, G., Wong, S. T., Tse, V., and Yeo, J. M. (2016h). Depolarization vs. repolarization: what is the mechanism of ventricular arrhythmogenesis underlying sodium channel haploinsufficiency in mouse hearts? Acta Physiol. (Oxf). doi: 10.1111/apha.12694. [Epub ahead of print].

Tse, G., Wong, S. T., Tse, V., and Yeo, J. M. (2016i). Determination of action potential wavelength restitution in Scn5a+/- mouse hearts modelling human Brugada syndrome. J. Physiol.

Tse, G., Wong, S. T., Tse, V., and Yeo, J. M. (2016j). Monophasic action potential recordings: which is the recording electrode? J. Basic Clin. Physiol. Pharmacol. doi: 10.1515/jbcpp-2016-0007. [Epub ahead of print].

Tse, G., Wong, S. T., Tse, V., and Yeo, J. M. (2016k). Restitution analysis of alternans using dynamic pacing and its comparison with S1S2 restitution in heptanol-treated, hypokalaemic Langendorff-perfused mouse hearts. Biomed. Rep. 4, 673-680. doi: 10.3892/br.2016.659

Tse, G., and Yan, B. P. (2016a). Novel arrhythmic risk markers incorporating QRS dispersion: QRSd x (Tpeak-Tend) / QRS and QRSd x (Tpeak-Tend) / (QT x QRS). Ann. Noninvasive Electrocardiol.

Tse, G., and Yan, B. P. (2016b). Traditional and novel electrocardiographic markers for predicting arrhythmic risk and sudden cardiac death. Europace.

Tse, G., and Yeo, J. M. (2015). Conduction abnormalities and ventricular arrhythmogenesis: the roles of sodium channels and gap junctions. Int. J. Cardiol. Heart Vasc. 9, 75-82. doi: 10.1016/j.ijcha.2015.10.003

Tse, G., Yeo, J. M., Tse, V., and Sun, B. (20161). Gap junction inhibition by heptanol increases ventricular arrhythmogenicity by decreasing conduction velocity without affecting repolarization properties or myocardial refractoriness in Langendorff-perfused mouse hearts. Mol. Med. Rep.

Vassiliou, V., Chin, C., Perperoglou, A., Tse, G., Ali, A., Raphael, C., et al. (2014). 93 Ejection fraction by cardiovascular magnetic resonance predicts adverse outcomes post aortic valve replacement. Heart 100, A53-A54. doi: 10.1136/heartjnl-2014-306118.93

Veeraraghavan, R., Lin, J., Hoeker, G. S., Keener, J. P., Gourdie, R. G., and Poelzing, S. (2015). Sodium channels in the $\mathrm{Cx} 43$ gap junction perinexus may constitute a cardiac ephapse: an experimental and modeling study. Pflugers Arch. 467, 2093-2105. doi: 10.1007/s00424-014-1675-z

Veeraraghavan, R., Poelzing, S., and Gourdie, R. G. (2014a). Intercellular electrical communication in the heart: a new, active role for the intercalated disk. Cell Commun. Adhes. 21, 161-167. doi: 10.3109/15419061.2014.905932

Veeraraghavan, R., Poelzing, S., and Gourdie, R. G. (2014b). Novel ligands for zipping and unzipping the intercalated disk: today's experimental tools, tomorrow's therapies? Cardiovasc. Res. 104, 229-230. doi: 10.1093/cvr/cvu216 
Veeraraghavan, R., Poelzing, S., and Gourdie, R. G. (2014c). Old cogs, new tricks: a scaffolding role for connexin 43 and a junctional role for sodium channels? FEBS Lett. 588, 1244-1248. doi: 10.1016/j.febslet.2014.01.026

Vigmond, E. J. (2005). The electrophysiological basis of MAP recordings. Cardiovasc. Res. 68, 502-503. doi: 10.1016/j.cardiores.2005.07.020

Vigmond, E. J., and Bardakjian, B. L. (1995). The effect of morphological interdigitation on field coupling between smooth muscle cells. IEEE Trans. Biomed. Eng. 42, 162-171. doi: 10.1109/10.341829

Vigmond, E. J., and Leon, L. J. (1999). Electrophysiological basis of monophasic action potential recordings. Med. Biol. Eng. Comput. 37, 359-365. doi: 10.1007/BF02513313

Vigmond, E. J., Tsoi, V., Yin, Y., Page, P., and Vinet, A. (2009). Estimating atrial action potential duration from electrograms. IEEE Trans. Biomed. Eng. 56, 1546-1555. doi: 10.1109/TBME.2009.2014740

Vitadello, M., Penzo, D., Petronilli, V., Michieli, G., Gomirato, S., Menabo, R., et al. (2003). Overexpression of the stress protein Grp94 reduces cardiomyocyte necrosis due to calcium overload and simulated ischemia. FASEB J. 17, 923-925. doi: 10.1096/fj.02-0644fje

Weber, P. A., Chang, H.-C., Spaeth, K. E., Nitsche, J. M., and Nicholson, B. J. (2004). The permeability of gap junction channels to probes of different size is dependent on connexin composition and permeant-pore affinities. Biophys. J. 87, 958-973. doi: 10.1529/biophysj.103.036350

Wehrens, X. H., Lehnart, S. E., Reiken, S. R., and Marks, A. R. (2004). $\mathrm{Ca} 2+/$ calmodulin-dependent protein kinase II phosphorylation regulates the cardiac ryanodine receptor. Circ. Res. 94, e61-e70. doi: 10.1161/01.RES.0000125626.33738.E2

Wei, H., Zhang, R., Jin, H., Liu, D., Tang, X., Tang, C., et al. (2010). Hydrogen sulfide attenuates hyperhomocysteinemia-induced cardiomyocytic endoplasmic reticulum stress in rats. Antioxid. Redox Signal. 12, 1079-1091. doi: $10.1089 /$ ars.2009.2898

Williams, G. S., Boyman, L., Chikando, A. C., Khairallah, R. J., and Lederer, W. J. (2013). Mitochondrial calcium uptake. Proc. Natl. Acad. Sci. U.S.A. 110, 10479-10486. doi: 10.1073/pnas.1300410110

Wingo, T. L., Shah, V. N., Anderson, M. E., Lybrand, T. P., Chazin, W. J., and Balser, J. R. (2004). An EF-hand in the sodium channel couples intracellular calcium to cardiac excitability. Nat. Struct. Mol. Biol. 11, 219-225. doi: $10.1038 /$ nsmb737

Witcher, D. R., Kovacs, R. J., Schulman, H., Cefali, D. C., and Jones, L. R. (1991). Unique phosphorylation site on the cardiac ryanodine receptor regulates calcium channel activity. J. Biol. Chem. 266, 11144-11152.

Wong, E. L., Woo, J., Hui, E., Chan, C., Chan, W. L., and Cheung, A. W. (2011). Primary care for diabetes mellitus: perspective from older patients. Patient Prefer. Adherence 5, 491-498. doi: 10.2147/PPA.S18687

Wong, W. T., Tian, X. Y., and Huang, Y. (2013). Endothelial dysfunction in diabetes and hypertension: cross talk in RAS, BMP4, and ROS-dependent COX-2-derived prostanoids. J. Cardiovasc. Pharmacol. 61, 204-214. doi: 10.1097/FJC.0b013e31827fe46e

Xie, W., Santulli, G., Guo, X., Gao, M., Chen, B. X., and Marks, A. R. (2013). Imaging atrial arrhythmic intracellular calcium in intact heart. J. Mol. Cell Cardiol. 64, 120-123. doi: 10.1016/j.yjmcc.2013.09.003

Xie, W., Santulli, G., Reiken, S. R., Yuan, Q., Osborne, B. W., Chen, B.-X., et al. (2015a). Mitochondrial oxidative stress promotes atrial fibrillation. Sci. Rep. 5:11427. doi: 10.1038/srep11427
Xie, Y., Liao, Z., Grandi, E., Shiferaw, Y., and Bers, D. M. (2015b). Slow $[\mathrm{Na}] \mathrm{i}$ changes and positive feedback between membrane potential and [Ca]i underlie intermittent early after depolarizations and arrhythmias. Circ. Arrhythm. Electrophysiol. 8, 1472-1480. doi: 10.1161/CIRCEP.115. 003085

Xu, L., Eu, J. P., Meissner, G., and Stamler, J. S. (1998). Activation of the cardiac calcium release channel (ryanodine receptor) by poly-S-nitrosylation. Science 279, 234-237. doi: 10.1126/science.279.5348.234

Yamamoto, M., Yang, G., Hong, C., Liu, J., Holle, E., Yu, X., et al. (2003). Inhibition of endogenous thioredoxin in the heart increases oxidative stress and cardiac hypertrophy. J. Clin. Invest. 112, 1395-1406. doi: 10.1172/JCI2003 17700

Yan, L.-J. (2014). Pathogenesis of chronic hyperglycemia: from reductive stress to oxidative stress. J. Diabetes Res. 2014, 11. doi: 10.1155/2014/137919

Yang, L., Korge, P., Weiss, J. N., and Qu, Z. (2010). Mitochondrial oscillations and waves in cardiac myocytes: insights from computational models. Biophys. J. 98, 1428-1438. doi: 10.1016/j.bpj.2009.12.4300

Yoshida, K., Ogata, K., Inaba, T., Nakazawa, Y., Ito, Y., Yamaguchi, I., et al. (2015). Ability of magnetocardiography to detect regional dominant frequencies of atrial fibrillation. J. Arrhythm. 31, 345-351. doi: 10.1016/j.joa.2015. 05.003

Zhang, Y., Liu, J., Luo, J. Y., Tian, X. Y., Cheang, W. S., Xu, J., et al. (2015). Upregulation of angiotensin (1-7)-mediated signaling preserves endothelial function through reducing oxidative stress in diabetes. Antioxid. Redox Signal. 23, 880-892. doi: 10.1089/ars.2014.6070

Zhou, L., Solhjoo, S., Millare, B., Plank, G., Abraham, M. R., Cortassa, S., et al. (2014). Effects of regional mitochondrial depolarization on electrical propagation: implications for arrhythmogenesis. Circ. Arrhythm. Electrophysiol. 7, 143-151. doi: 10.1161/CIRCEP.113.000600

Zima, A. V., Copello, J. A., and Blatter, L. A. (2004). Effects of cytosolic $\mathrm{NADH} / \mathrm{NAD}(+)$ levels on sarcoplasmic reticulum $\mathrm{Ca}(2+)$ release in permeabilized rat ventricular myocytes. J. Physiol. 555, 727-741. doi: 10.1113/jphysiol.2003.055848

Zorov, D. B., Filburn, C. R., Klotz, L. O., Zweier, J. L., and Sollott, S. J. (2000). Reactive oxygen species (ROS)-induced ROS release: a new phenomenon accompanying induction of the mitochondrial permeability transition in cardiac myocytes. J. Exp. Med. 192, 1001-1014. doi: 10.1084/jem.192. 7.1001

Conflict of Interest Statement: The authors declare that the research was conducted in the absence of any commercial or financial relationships that could be construed as a potential conflict of interest.

The reviewer QY and handling Editor declared their shared affiliation, and the handling Editor states that the process nevertheless met the standards of a fair and objective review.

Copyright (c) 2016 Tse, Yan, Chan, Tian and Huang. This is an open-access article distributed under the terms of the Creative Commons Attribution License (CC BY). The use, distribution or reproduction in other forums is permitted, provided the original author(s) or licensor are credited and that the original publication in this journal is cited, in accordance with accepted academic practice. No use, distribution or reproduction is permitted which does not comply with these terms. 